\title{
Evaluation of the Effects of Toxoplasmosis in Small Ruminants on the Epidemiology of Human Toxoplasmosis by Indirect ELISA in Kaleybar Region, North West of Iran
}

\author{
Yaghoub Firouzivand $^{1 * \mathbb{D}}$, Behrad Khan Ahmadi $^{\circledR}$, Mustafa Afsari ${ }^{3}$ \\ 'Department of Pathobiology, Malekan Branch, Islamic Azad University, Malekan, Iran \\ ${ }^{2}$ Clinical Research Development Center, Imam Khomeini and Mohammad Kermanshahi and Farabi Hospitals, Kermanshah \\ University of Medical Sciences, Kermanshah, Iran \\ ${ }^{3}$ Young Researchers Club, Shabestar Branch, Islamic Azad University, Shabestar, Iran
}

\begin{abstract}
Introduction: Toxoplasma gondii is an intracellular protozoan that causes toxoplasmosis in humans and domestic animals. It causes abortion, especially in small ruminants. Sheep and goats have a significant role in the maintenance and survival of the parasite as well as its transmission to humans. Therefore, the aim of this study was to evaluate the seroprevalence of toxoplasmosis in small ruminants in Kaleybar region, East Azerbaijan province, using Indirect ELISA.

Materials and Methods: In this study, blood samples of 270 sheep and goats were collected from October 2019 to December 2019 and anti-Toxoplasma IgG antibodies in sera were evaluated using indirect ELISA. Data analysis was performed using chisquare test in SPSS version 24.0. A $P$ value of less than 0.05 was considered statistically significant.

Results: Totally, 26 of $270(9.62 \%)$ animals had anti-Toxoplasma gondii antibodies in their sera. Analysis showed that sheep were more susceptible to toxoplasmosis than goats and $21(10.5 \%)$ sheep and $5(7.14 \%)$ goats were seropositive for $T$. gondii; however, there was no statistically significant difference $(P=0.413)$. The highest frequency $(15.87 \%)$ of infection was observed in sheep and goats aged 3-4 years, respectively. Moreover, the rate of infection was higher in female (22/205) animals than in males (4/65); however, the relationship between gender and age and the frequency of positive samples was not significant $(P=0.276$ and $P=0.121$ ).

Conclusions: The results of this study indicated that the seroprevalence of Toxoplasma gondii infection in small ruminants of the Kaleybar region (North West of Iran) is relatively low compared to other parts of the country. Further studies should be conducted on the rate of infection in definitive hosts of $T$. gondii in the region as a potential source of human infection.

Keywords: Epidemiology, Toxoplasmosis, ELISA, Kaleybar region, Iran
\end{abstract}

Received: June 12, 2020 , Accepted: August 5, 2020, ePublished: October 14, 2020

\section{Introduction}

Toxoplasma gondii, an obligate intracellular protozoan parasite (phylum Apicomplexa, subclass Coccidia), infects many different types of hosts and different host tissues, and it is the causative agent of toxoplasmosis (1). The parasite is only able to complete its sexual life cycle in felids as definitive hosts and oocysts produced are excreted through the feces of the host. Sporulated oocysts contaminate the surrounding environment and pastures $(2,3)$. Toxoplasmosis is a serious health problem in many parts of the world (4).

According to studies, the global rate of human toxoplasmosis is between $1.3 \%$ and $98.4 \%$ (5), in addition to the fact that more than $30 \%$ of Iranians are infected with Toxoplasma gondii (6).
Toxoplasmosis is one of the most important parasitic zoonotic diseases, so it has been the most commonly studied coccidian parasite (7).

Sheep and goats acquire the infection after contact with infected cats and ingesting oocytes scattered in the environment (8) or by ticks (9). In the intermediate hosts, even the ingestion of 10 sporulated oocysts can cause infection.

In addition, lambs and goat kids can be exposed to $T$. gondii by consuming the milk of ewes and goats naturally infected with the parasite and the establishment of $T$. gondii infection in the muscles of lambs and even eating small pieces (5-10 g) of their uncooked meat can transmit the infection to humans (10). Human infection occurs in a variety of ways, such as ingesting sporulated oocytes 
released in water and food or by consuming undercooked or uncooked meat containing viable T. gondii cysts (1012), as well as vertical transmission (13). Toxoplasmosis causes serious complications in humans, especially neonates, as well as immunocompromised individuals $(14,15)$.

Generally, small ruminants are highly susceptible to T. gondii infection. The infection is not associated with any specific symptoms (16); however, the main problem for pregnant animals is that the parasite causes early embryonic death, foetal resorption, mummification, stillbirth $(10,17)$ that lead to significant economic and reproductive losses $(18,19)$. In sheep, infection with the parasite in early pregnancy poses a greater risk to the fetus compared to late pregnancy (20). In many countries including Iran, breeding livestock such as sheep and goats is booming and the milk and meat of these animals are widely used as food sources (21). Toxoplasmosis of goats and sheep is affecting the lives of people whose source of income is the production of ruminant meat and milk (22).

Considering the role of sheep and goats in maintaining and transmitting the infection to humans, research on the detection of T. gondii infection in livestock for human consumption is very important (2).

Many studies on toxoplasmosis in small ruminants have been performed in different regions of the world.

According to previous studies, the prevalence of toxoplasmosis ranges between 3\% and 98\% (2) in sheep herds and it ranges from $5.6 \%$ to $62 \%$ in goats around the world (2). In seroprevalence studies conducted on sheep and goats in different areas of Iran for T. gondii, seropositivity was determined to be between $3.3 \%$ and $36.8 \%$ in sheep $(23)$ and $27 \%$ in goats, respectively (19). In general, various methods are used to diagnose toxoplasmosis, including direct methods (such as immunohistochemistry, histopathology, and PCR) and indirect methods (such as indirect fluorescent antibody test, Sabin-Feldman dye test, ELISA, and hemagglutination test) (24). In live animals, the ELISA method can be used as a suitable test to detect antibodies against T. gondii (25). Considering the economic importance of abortion in sheep and goat herds and the possibility of transmitting the disease to humans via the consumption of livestock products, this study was performed to evaluate the seroprevalence of toxoplasmosis in small ruminants for the first time in Kaleybar region, East Azerbaijan province.

\section{Materials and Methods}

\section{Study Area}

Kaleybar region is located in the northeast of East Azerbaijan province with a population of about 48837, at $38^{\circ} 52^{\prime}$ North latitude and $47^{\circ} 25^{\prime}$ East longitude from the meridian, and its altitude from sea level is $1144 \mathrm{~m}$. Its area is about $3,702 \mathrm{~km}^{2}$ with a mean annual rainfall of $372 \mathrm{~mm}$ and its mean temperature varies from 2.2 to $23.9^{\circ} \mathrm{C}$. The climate of Kaleybar is cold and temperate. Agriculture and animal husbandry are flourishing in this region.

\section{Blood Sample Collection}

Blood samples of 270 randomly selected animals (200 sheep and 70 goats) were collected from October to December 2019. For the evaluation of seropositivity, $5 \mathrm{~mL}$ of blood was drawn from the jugular vein using sterile disposable syringes. After blood sampling, specimens were centrifuged at $3000 \times$ for 10 minutes and immediately after the separation of serum, these serums were kept in sterile microtubes at $-20^{\circ} \mathrm{C}$ until use for serological examinations. Serum samples were evaluated in the laboratory by ELISA.

\section{Indirect ELISA}

Indirect ELISA method was used according to the protocol provided by Izadyar et al in 2019 (26) with some modifications. In brief, 96-well Strip Microplate (SPL, Korea) was coated with $100 \mu \mathrm{L}$ of antigen $(90 \mu \mathrm{g} / \mathrm{mL})$ in buffer (NaHCO3 - Na2CO3, pH 9.6) and the overnight incubation was performed at $4^{\circ} \mathrm{C}$. After the wells were washed thrice with TBS, the blocking was performed at room temperature for 2 hours using 1\% bovine serum albumin in PBS. The wells were then washed with TBS three times as mentioned above and then $100 \mu \mathrm{L}$ of serum samples from sheep and goats and from positive and negative controls were added to each well after dilution and incubated at $37^{\circ} \mathrm{C}$ for 1 hour. After incubation, the wells were washed and $100 \mu \mathrm{L}$ of 1:5000 dilution of HRP (rabbit anti-sheep/goat IgG-horseradish peroxidase) conjugated antibody (Razi BioTech, Iran) was added to each well and incubated for 1 hour at $37^{\circ} \mathrm{C}$. Eventually, the wells were washed five times with TBS, and $50 \mu \mathrm{L}$ of 3,3',5,5'-tetramethylbenzidine (TMB) substrate solution (Razi BioTech, Iran) was added and incubated in the dark for 20 minutes at room temperature. To stop the reaction, $25 \mu \mathrm{L}$ of $2 \mathrm{M} \mathrm{H} 2 \mathrm{SO} 4$ (stop solution) was added to each well after 10 minutes. Optical density (OD) at $450 \mathrm{~nm}$ was measured using ELISA reader (Stat Fax, USA).

\section{Statistical Analysis}

Statistical analysis of the data was performed using chisquare test in SPSS version 24.0.

\section{Results}

Totally, the sera of 270 animals (200 sheep and 70 goats) were examined and $10.5 \%$ (21/200) of sheep and $7.14 \%$ (5/70) of goats were seropositive for T. gondii; however, no statistically significant relationship was found between animal species and serum positivity $(P=0.413)$.

Serological results are summarized in Table 1.

Considering the age of animals, the highest and lowest number of positive cases were found in the age groups of 3-4 years (15.87\%) and 1-2 years (5.26\%), respectively; however, the relationship between age and frequency of positive cases of toxoplasmosis was not significant 
Table 1. Prevalence of T. gondii in Small Ruminants of Kaleybar Region (Northeast of East Azerbaijan province)

\begin{tabular}{lcccc}
\hline Risk factors & Total & $\begin{array}{c}\text { No. of Positive } \\
\text { samples }\end{array}$ & $\begin{array}{c}\text { No. of Negative } \\
\text { samples }\end{array}$ & P Value \\
\hline Species & & & & $0.413^{*}$ \\
Sheep & 200 & $21(10.5 \%)$ & $179(89.5 \%)$ & \\
Goat & 70 & $5(7.14 \%)$ & $65(92.85 \%)$ & \\
Total & 270 & $26(9.62 \%)$ & $244(90.37 \%)$ & \\
Age & & & & 0.121 \\
1-2 years & 57 & $3(5.26 \%)$ & $54(94.73 \%)$ & \\
$>2$ years & 150 & $13(8.66 \%)$ & $137(91.33 \%)$ & \\
3-4 years & 63 & $10(15.87 \%)$ & $53(84.12 \%)$ & \\
Gender & & & & \\
Female & 205 & $22(10.73 \%)$ & $183(89.26 \%)$ & \\
Male & 65 & $4(6.15 \%)$ & $61(93.84 \%)$ & \\
\hline
\end{tabular}

* Statistically significant at $P<0.05$.

\section{$(P=0.121)$.}

As shown in Table 1, the infection rate of the female $(22 / 205)$ animals was higher than that of males $(4 / 65)$; however, there was no significant relationship between gender and the frequency of positive samples $(P=0.276)$.

\section{Discussion}

Toxoplasma gondii is a zoonotic intracellular parasite that infects many warm-blooded animals and humans (16).

It is estimated that anti-Toxoplasma antibodies are present in one-third of the people in the world $(7,27)$. The ingestion of the meat of farm animals infected with $T$. gondii tissue cysts as well as drinking the milk of infected goats can cause human infection (28).

Since the consumption of meat has a special role in providing dietary protein in Iran, eating uncooked or undercooked meat is an important risk factor for parasitic infections in humans, so the seropositivity of T. gondii is lower in people who consume thoroughly cooked meat than in people who consume it raw (29). Among meatproducing domestic animals, sheep and goats are more susceptible to $T$. gondii infection than other livestock $(7,30)$.

In Iran, sheep and goats are mostly raised by free grazing, so these animals increase the chance of cyst formation in their tissues by ingesting sporulated oocytes scattered in the environment.

Various studies revealed that the prevalence of toxoplasmosis in sheep and goats in different regions of Iran ranges from $33.62 \%(153 / 455)$ to $36.41 \%(130 / 375)$ (26), $24.8 \%$ to $10.6 \%$ (31), $29.5 \%$ to $18.8 \%$ (32), $16.7 \%$ to $8.08 \%$ (33), $13.8 \%$ to $13.1 \%$ (34), $30 \%$ to $15 \%$ (35), 3.3 $\%$ to $1.7 \%(36), 12.2 \%$ to $4.4 \%$ (37), and $30 \%(60 / 200)$ to $15 \%(30 / 200)$ (38), respectively. According to reports, anti-Toxoplasma antibodies are present in $39.3 \%$ of Iranians and $43 \%$ of pregnant women also have anti- $T$. gondii antibodies; therefore, $57 \%$ of these people were susceptible to acute toxoplasmosis (6). According to previous studies conducted in different countries of the world, the overall estimated prevalence was reported to be $49.35 \%$ (3.0-95.7\%) (39) for sheep and 22.9\% (5.6-89.0\%) (2) for goats.

In this study, the serological prevalence of toxoplasmosis in sheep and goats in Kaleybar region (East Azerbaijan province) was detected to be $10.5 \%$ and $7.14 \%$, respectively. In addition to the method used to detect the infection, weather conditions, gender, age, cat density, as well as livestock breeding can affect the prevalence of T. gondii $(23,40)$. A previous study performed in Tabriz (located in north-western Iran) showed that the prevalence of T. gondii in sheep and goats was $24.8 \%$ and $10.6 \%(31)$, respectively, which is higher compared to the present study. This may be related to the reasons mentioned above.

In the present study, it was found that the frequency of infection is higher in animals aged 3-4 years (15.87\%) than those aged $1-2$ and $2-3$ years (5.26\% and $8.66 \%$ ). However, no significant relationship was found between age groups and frequency of infection $(P=0.121)$.

Numerous studies have reported higher rates of $T$. gondii infection in adult animals than in younger ones (26,41-43), which is similar to the findings of the present study. This can be related to the exposure of adult animals to predisposing factors compared to younger animals (44, 45).

Some studies including those conducted by Bahrieni et al on small ruminants in southeastern Iran (46), de Moura et al on goats in Brazil (47), and Gebremedhin et al on sheep in Ethiopia (48) show that susceptibility to toxoplasma is higher in females than in males. However, in the current study, no statistically significant relationship was found between gender and the seroprevalence of toxoplasmosis (0.276), which is consistent with many other studies (49-53). It seems that gender does not appear to play an important role in toxoplasmosis, and in epidemiological studies, it is considered as a confounding factor (54).

\section{Conclusions}

The findings of this study showed that the seroprevalence of toxoplasmosis in small ruminants in the Kaleybar region is relatively low compared to other parts of Iran, which may be due to climatic conditions and the way of keeping and breeding livestock. In addition, in this study, it was found that the rate of infection and susceptibility of sheep is higher compared to goats, which is important given that consumption of less cooked or uncooked mutton increases the risk of human infection with $T$. gondii.

High seropositivity in adult livestock indicates the acquired contamination of the livestock by horizontal transmission as well as exposure to most of these intermediate hosts and oocytes scattered in the 
environment and pasture. Numerous factors affect the epidemiology of toxoplasmosis in humans and animals, such as livestock breeding, spread of oocytes by infected cats in the environment, favorable situations for oocyte sporulation (such as climate, etc.), the hygiene status of slaughterhouses, food processing technology, and feeding habits.

Although in many cases, the source of human infection is unknown, preventive measures such as cooking meat thoroughly $\left(67^{\circ} \mathrm{C}\right)$, freezing it before consumption $\left(-12^{\circ} \mathrm{C}\right.$ and less), and improving kitchen hygiene can prevent the transmission of infection by food. In some cases, the implementation of educational programs for farmers and other members of society, especially women, has an effective role in reducing the rate of infection. Further studies are required to investigate the infection of domestic and stray cats (a potential cause of oocyte proliferation) with the parasite and determine the percentage of contamination of meat consumed (an important factor in the infection of people, especially people at risk), which can help assess the overall prevalence of toxoplasmosis in this area.

\section{Conflict of Interests}

The authors declare no competing interests.

\section{Ethical Issues}

In this research, ethical considerations have been fully observed.

\section{Acknowledgment}

The authors extend their thanks to Clinical Research Development Center of Imam Khomeini and Mohammad Kermanshahi and Farabi hospitals affiliated to Kermanshah University of Medical Sciences for their kind support.

\section{Authors' Contributions}

YF did the writing and editing of the manuscript. BKA designed and did the data collection. MA designed the study and did data collection and statistical analysis.

\section{Funding}

The authors received no financial support for the research, authorship, and publication of this article.

\section{References}

1. Dubey JP, Beattie CP. Toxoplasmosis of Animals and Man. CRC Press; 1988.

2. Stelzer S, Basso W, Benavides Silván J, et al. Toxoplasma gondii infection and toxoplasmosis in farm animals: Risk factors and economic impact. Food Waterborne Parasitol. 2019;15:e00037. doi: 10.1016/j.fawpar.2019.e00037.

3. Schlüter D, Däubener W, Schares G, Groß U, Pleyer U, Lüder C. Animals are key to human toxoplasmosis. Int J Med Microbiol. 2014;304(7):917-29. doi: 10.1016/j. ijmm.2014.09.002.

4. Armand B, Solhjoo K, Shabani-Kordshooli M, Davami $\mathrm{MH}$, Sadeghi M. Toxoplasma infection in sheep from south of Iran monitored by serological and molecular methods; risk assessment to meat consumers. Vet World. 2016;9(8):850-5. doi: 10.14202/vetworld.2016.850-855.

5. Ducrocq J, Simon A, Lemire M, De Serres G, Lévesque
B. Exposure to Toxoplasma gondii through consumption of raw or undercooked meat: a systematic review and meta-analysis. Vector Borne Zoonotic Dis. 2021;21(1):40-9. doi: 10.1089/ vbz.2020.2639.

6. Daryani A, Sarvi S, Aarabi M, et al. Seroprevalence of Toxoplasma gondii in the Iranian general population: a systematic review and meta-analysis. Acta Trop. 2014;137:185-94. doi: 10.1016/j. actatropica.2014.05.015.

7. Tenter AM, Heckeroth AR, Weiss LM. Toxoplasma gondii: from animals to humans. Int J Parasitol. 2000;30(12-13):1217-58. doi: 10.1016/s0020-7519(00)00124-7.

8. Ducournau C, Moiré N, Carpentier R, et al. Effective nanoparticlebased nasal vaccine against latent and congenital toxoplasmosis in sheep. Front Immunol. 2020;11:2183. doi: 10.3389/ fimmu.2020.02183.

9. Kim JY, Kwak YS, Lee IY, Yong TS. Molecular detection of Toxoplasma gondii in Haemaphysalis ticks in Korea. Korean J Parasitol. 2020;58(3):327-31. doi: 10.3347/kjp.2020.58.3.327.

10. Dubey JP, Murata FHA, Cerqueira-Cézar CK, Kwok OCH, Su C. Economic and public health importance of Toxoplasma gondii infections in sheep: the last decade. Vet Parasitol X. 2020:100028. doi: 10.1016/j.vpoa.2020.100028.

11. Cook AJ, Gilbert RE, Buffolano W, et al. Sources of Toxoplasma infection in pregnant women: European multicentre case-control study. European Research Network on Congenital Toxoplasmosis. BMJ. 2000;321(7254):142-7. doi: 10.1136/bmj.321.7254.142.

12. Kijlstra A, Jongert $E$. Control of the risk of human toxoplasmosis transmitted by meat. Int J Parasitol. 2008;38(12):1359-70. doi: 10.1016/j.ijpara.2008.06.002.

13. Gajadhar AA, Scandrett WB, Forbes LB. Overview of food- and water-borne zoonotic parasites at the farm level. Rev Sci Tech. 2006;25(2):595-606.

14. Kolören Z, Dubey JP. A review of toxoplasmosis in humans and animals in Turkey. Parasitology. 2020;147(1):12-28. doi: 10.1017/ s0031182019001318.

15. McAuley JB. Congenital toxoplasmosis. J Pediatric Infect Dis Soc. 2014;3 Suppl 1:S30-5. doi: 10.1093/jpids/piu077.

16. Dubey JP. Toxoplasmosis of Animals and Humans. CRC Press; 2016.

17. Givens MD, Marley MS. Infectious causes of embryonic and fetal mortality. Theriogenology. 2008;70(3):270-85. doi: 10.1016/j. theriogenology.2008.04.018.

18. Dubey JP, Sundar N, Hill D, et al. High prevalence and abundant atypical genotypes of Toxoplasma gondii isolated from lambs destined for human consumption in the USA. Int J Parasitol. 2008;38(8-9):999-1006. doi: 10.1016/j.ijpara.2007.11.012.

19. Sharif M, Sarvi S, Shokri A, et al. Toxoplasma gondii infection among sheep and goats in Iran: a systematic review and metaanalysis. Parasitol Res. 2015;114(1):1-16. doi: 10.1007/s00436014-4176-2.

20. Benavides J, Fernández $M$, Castaño $P$, Ferreras MC, Ortega-Mora L, Pérez V. Ovine toxoplasmosis: a new look at its pathogenesis. J Comp Pathol. 2017;157(1):34-8. doi: 10.1016/j.jcpa.2017.04.003.

21. Abu-Dalbou MA, Ababneh MM, Giadinis ND, Lafi SQ. Ovine and caprine toxoplasmosis (Toxoplasma gondii). 2010. Iran J Vet Sci Technol. 2010;2(2):16-61. doi: 10.22067/veterinary.v2i2.8378.

22. Khan AH, Noordin R. Serological and molecular rapid diagnostic tests for Toxoplasma infection in humans and animals. Eur J Clin Microbiol Infect Dis. 2020;39(1):19-30. doi: 10.1007/s10096-01903680-2.

23. Chaechi Nosrati MR, Shemshadi B, Shayan P, Ranjbar Bahadory $\mathrm{S}$, Eslami A. Serological determination of Toxoplasma gondii in sheep Ovis aries in Gilan province North of Iran. Arch Razi Inst. 2021;75(4):463-71. doi: 10.22092/ari.2019.127291.1383.

24. Liu Q, Wang ZD, Huang SY, Zhu XQ. Diagnosis of toxoplasmosis and typing of Toxoplasma gondii. Parasit Vectors. 2015;8:292. doi: 10.1186/s13071-015-0902-6.

25. Özmutlu Çakmak D, Karatepe B. Seroprevalence of Toxoplasma gondii in sheep from Nevșehir province in Turkey. Turkiye Parazitol 
Derg. 2017;41(3):148-51. doi: 10.5152/tpd.2017.5245.

26. Izadyar N, Abd Nikfarjam B, Esmaeili Rastaghi AR, Alizadeh SA Heydarian P, Saraei M. A serologic study on Toxoplasma gondii infection in slaughtered sheep and goats in Qazvin province, Iran. Trop Anim Health Prod. 2019;51(5):1289-93. doi: 10.1007/ s11250-019-01832-2.

27. Dubey JP. Toxoplasmosis, Sarcocystosis, Isosporosis, and Cyclosporosis. Zoonoses; 1998.

28. Jones JL, Dargelas V, Roberts J, Press C, Remington JS, Montoya JG. Risk factors for Toxoplasma gondii infection in the United States. Clin Infect Dis. 2009;49(6):878-84. doi: 10.1086/605433.

29. Mizani A, Alipour A, Sharif M, et al. Toxoplasmosis seroprevalence in Iranian women and risk factors of the disease: a systematic review and meta-analysis. Trop Med Health. 2017;45:7. doi: 10.1186/s41182-017-0048-7.

30. Jithendran KP. Seroprevalence of Toxoplasma antibodies in domestic animals-an indicator of Toxoplasma gondii in the environment and human. ENVIS Bulletin Himalayan Ecology. 2004;12:22-8.

31. Kavari A, Nowzari N, Moazeni Jula G, Moazeni Jula F, Hashemzadeh H. A serological and molecular study on Toxoplasma gondii infection in sheep and goat in Tabriz. Arch Razi Inst. 2013;68(1):29-35. doi: 10.7508/ari.2013.01.005.

32. Asgari Q, Sarkari B, Amerinia M, Panahi S, Mohammadpour I, Sadeghi Sarvestani A. Toxoplasma infection in farm animals: a seroepidemiological survey in Fars province, south of Iran. Jundishapur J Microbiol. 2013;6(3):269-72. doi: 10.5812/jjm.5195.

33. Ghorbani M, Hafizi A, Shegerfcar MT, et al. Animal toxoplasmosis in Iran. J Trop Med Hyg. 1983;86(2):73-6.

34. Hoghooghi-Rad N, Afraa M. Prevalence of toxoplasmosis in humans and domestic animals in Ahwaz, capital of Khoozestan province, south-west Iran. J Trop Med Hyg. 1993;96(3):163-8.

35. Ghazaei C. Serological survey of antibodies to Toxoplasma gondii. Afr J Health Sci. 2006;13(1-2):131-4.

36. Derakhshan M, Mousavi M. Serological survey of antibodies to Toxoplasma gondii in cats, goats, and sheep in Kerman, Iran. Comp Clin Path. 2014;23(2):267-8. doi: 10.1007/s00580-012-1605-4.

37. Rasti S, Marandi N, Abdoli A, Delavari M, Mousavi SGA. Serological and molecular detection of Toxoplasma gondii in sheep and goats in Kashan, Central Iran. J Food Saf. 2018;38(2):e12425. doi: $10.1111 /$ jfs. 12425 .

38. Muula AS. Serological survey of antibodies to Toxoplasma gondii. Afr J Health Sci. 2006;13(1-2):131-134. doi: 10.4314/ajhs. v13i1.30827.

39. Dubey JP. Toxoplasmosis in sheep--the last 20 years. Vet Parasitol. 2009;163(1-2):1-14. doi: 10.1016/j.vetpar.2009.02.026.

40. Dubey JP. Toxoplasmosis - a waterborne zoonosis. Vet Parasitol. 2004;126(1-2):57-72. doi: 10.1016/j.vetpar.2004.09.005.

41. van der Puije WN, Bosompem KM, Canacoo EA, Wastling JM, Akanmori BD. The prevalence of anti-Toxoplasma gondii antibodies in Ghanaian sheep and goats. Acta Trop. 2000;76(1):21-6. doi: 10.1016/s0001-706x(00)00084-x.

42. Ahmed H, Malik A, Arshad M, et al. Seroprevalence and spatial distribution of toxoplasmosis in sheep and goats in North-Eastern Region of Pakistan. Korean J Parasitol. 2016;54(4):439-46. doi: 10.3347/kjp.2016.54.4.439.

43. Andrade MM, Carneiro M, Medeiros AD, Andrade Neto V, Vitor RW. Seroprevalence and risk factors associated with ovine toxoplasmosis in Northeast Brazil. Parasite. 2013;20:20. doi: 10.1051/parasite/2013019.

44. Anderlini GA, Mota RA, Faria EB, et al. Occurrence and risk factors associated with infection by Toxoplasma gondii in goats in the State of Alagoas, Brazil. Rev Soc Bras Med Trop. 2011;44(2):157-62. doi: 10.1590/s003786822011005000017.

45. Cenci-Goga BT, Ciampelli A, Sechi P, et al. Seroprevalence and risk factors for Toxoplasma gondii in sheep in Grosseto district, Tuscany, Italy. BMC Vet Res. 2013;9:25. doi: 10.1186/1746-6148-9-25.

46. Bahrieni M, Fasihi Harandi M, Beigzadeh M, Kamyabi H, Zia-Ali N. Risk factors analysis associated with seropositivity to Toxoplasma gondii in sheep and goats in Southeastern Iran using modified agglutination test (MAT). Iran J Parasitol. 2008;3(1):38-43.

47. deMoura AB, RibeiroA, de Souza AP, etal. Seroprevalence and risk factors for Toxoplasma gondii infection in goats in Southern Brazil. Acta Sci Vet. 2016;44(1):1-7.

48. Gebremedhin EZ, Agonafir A, Tessema TS, et al. Seroepidemiological study of ovine toxoplasmosis in East and West Shewa Zones of Oromia regional state, Central Ethiopia. BMC Vet Res. 2013;9:117. doi: 10.1186/17466148-9-117.

49. Deksne G, Ligere B, Šneidere A, Jokelainen P. Seroprevalence and Factors Associated with Toxoplasma gondii Infections in Sheep in Latvia: Latvian Dark Headed Sheep Breed Associated with Higher Seroprevalence. Vector Borne Zoonotic Dis. 2017;17(7):478-82. doi: 10.1089/vbz.2016.2003.

50. Gazzonis AL, Veronesi F, Di Cerbo AR, et al. Toxoplasma gondii in small ruminants in Northern Italy - prevalence and risk factors. Ann Agric Environ Med. 2015;22(1):628. doi: 10.5604/12321966.1141370.

51. Zhang N, Wang S, Wang D, et al. Seroprevalence of Toxoplasma gondii infection and risk factors in domestic sheep in Henan province, central China. Parasite. 2016;23:53. doi: 10.1051/parasite/2016064.

52. Magalhães FJ, Ribeiro-Andrade M, Alcântara AM, et al. Risk factors for Toxoplasma gondii infection in sheep and cattle from Fernando de Noronha Island, Brazil. Rev Bras Parasitol Vet. 2016;25(4):511-5. doi: 10.1590/s198429612016051.

53. Alvarado-Esquivel C, Romero-Salas D, García-Vázquez $\mathrm{Z}$, et al. Seroprevalence and correlates of Toxoplasma gondii infection in domestic pigs in Veracruz State, Mexico. Trop Anim Health Prod. 2014;46(4):705-9. doi: 10.1007/s11250-014-0551-3.

54. Thrusfield M. Veterinary Epidemiology. John Wiley \& Sons; 2018.

(C) 2020 The Author(s); This is an open-access article distributed under the terms of the Creative Commons Attribution License (http:// creativecommons.org/licenses/by/4.0), which permits unrestricted use, distribution, and reproduction in any medium, provided the original work is properly cited. 